Special issue of the International Conference on Computational and Experimental Science and Engineering (ICCESEN 2014)

\title{
Analysis of Drought Events - Case Study for Blanice River Catchment (Czech Republic)
}

\author{
V. DAVID* AND T. DAVIDOVA \\ Czech Technical University in Prague, Faculty of Civil Engineering, Department of Irrigation, \\ Drainage and Landscape Engineering, Prague, Czech Republic
}

\begin{abstract}
Expected results of considered climate changes consist mainly in the more frequent flood events having higher magnitudes as well as in more frequent periods of droughts with longer duration in conditions of Czech Republic as well as in neighbouring countries. This can result in losses caused by both floods and droughts. The procedures for flood frequency analysis are clear and well established while droughts cannot be defined and analysed without consideration of conditions in given regions. It is therefore necessary to analyse time series in order to define both meteorological and hydrological droughts as well as their coincidence in statistical manner. The purpose of this analysis consists besides others in the correct planning of drought mitigation policies. As a case study area, the catchment of Blanice River has been chosen. This catchment has an area of $534 \mathrm{~km}^{2}$ and is located about $40 \mathrm{~km}$ southeast of Prague. For the analysis, the data from three discharge gauging stations and three meteorological stations were used. The daily time series of discharges, precipitations and temperatures used for the analysis were all 50 years long. The analyses needed to be carried out with the consideration of different durations of drought periods in order to define drought before it could be analysed from the point of view of trends. In general, trends were identified in analysed data with respect to annual values which can be understood to be in agreement with considered climate changes. However, no significant trend was identified in drought with respect to their total annual duration.
\end{abstract}

DOI: 10.12693/APhysPolA.128.B-317

PACS: 92.40.De, 92.40.Ea, 92.40.Fb

\section{Introduction}

Expected climate change is considered to have besides others an impact on the temporal distribution of precipitation. More frequent occurrence of droughts is considered as one of expected impacts of such climate change in Central Europe. Droughts are expected to occur with increased frequency and longer duration according to many studies [1]. This can have very important consequences with respect to societies [2]. The most important are agriculture $[3,4]$ and water supply but also ecosystems cannot be omitted. Thus, it is very important to set robust procedures for drought identification and quantify trends. This is supposed to be a very important part of activities for mitigation of climate change impacts. In this contribution, the case study for Blanice River catchment is presented. The study focuses on the identification of droughts from both meteorological and hydrological point of view and on the identification of trends which can have an important influence on drought severity in future in conditions of Czech Republic.

\section{Material and methods}

As a study area, catchment of Blanice River was chosen as it is the area of interest for many other research activities carried out by the team from the Department of Irrigation, Drainage and Landscape Engineering. This

*corresponding author; e-mail: vaclav.david@fsv.cvut.cz catchment is located $40 \mathrm{~km}$ southeast of Prague in Central Bohemia Region and has a total area $534 \mathrm{~km}^{2}$.

For purposes of this study, the data for three discharge gauging stations, two precipitation gauging stations and one temperature gauging station were used which are located in Blanice River catchment. In case of discharge data, the longest data series (55 yrs) was available for Radonice station located close to the catchment outlet at the confluence to Sázava River. The data from other two stations cover much shorter period which is 10 yrs for Louňovice pod Blaníkem station and 5 yrs for Slověnice station. Meteorological data were available for two precipitation gauging stations (Veliš and Postupice) and for one temperature gauging station (Hlasivo) covering a period of 52 years.

The data were first analysed using standard statistical procedures to get the values of 355-day discharges $\left(Q_{355 d}\right)$ which are considered as a limit defining short term drought conditions. Second step consisted in the analysis of trends of both meteorological and hydrological data with respect to their annual averages or totals. The analysis was carried out using Mann-Kendall test $[5,6]$.

The identification of droughts was based on Antecedent Precipitation Index (API) in case of precipitation data and on $Q_{355 d}$. Droughts were then assessed in terms of annual totals of duration over the whole period of records. API is used in different forms. In this case, the simpler version was used which is defined as a precipitation total in preceding period of given duration $\left(A P I_{m}=\sum_{i=1}^{m} P_{t-i}\right)$, 
where $m$ defines the duration of preceding period and $P_{t-i}$ is precipitation total in $i$ th day before the day for which API is calculated. Droughts were then analysed as annual total durations for trends.

\section{Results}

The results of the analysis of mean annual precipitation totals show gentle growth over the period which is more significant for Postupice $(Z=1.87)$ than for Veliš $(Z=1.60)$ although its significance is not high. The growth of precipitation totals for Veliš and Postupice is 1.8 and $2.2 \mathrm{~mm} /$ year respectively (see Figure 1). Another case is the mean annual temperature for which very significant growth $(Z=4.47)$ over the whole period of records was identified but being very slow $\left(0.03^{\circ} \mathrm{C} /\right.$ year $)$. Regarding mean annual discharges, only data for Radonice were analysed from the point of view of trends as other two stations have too short records (see Fig. 2). For Radonice, slight decrease was identified being not significant $(Z=-0.67)$.

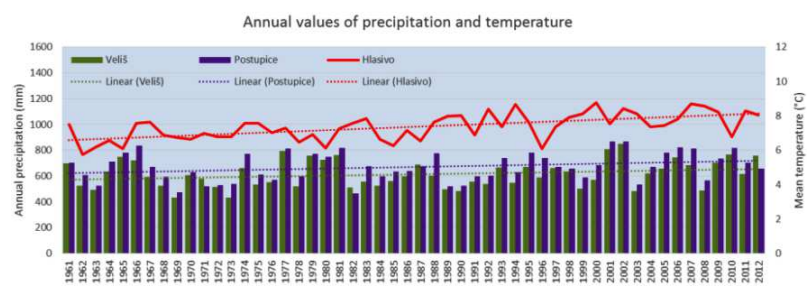

Fig. 1. Annual values of precipitation total and mean temperature.

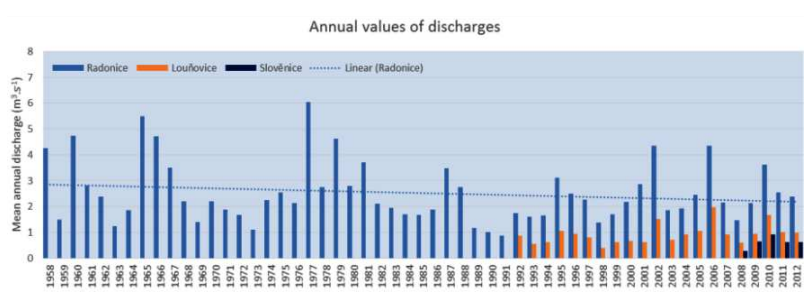

Fig. 2. Mean annual discharges.

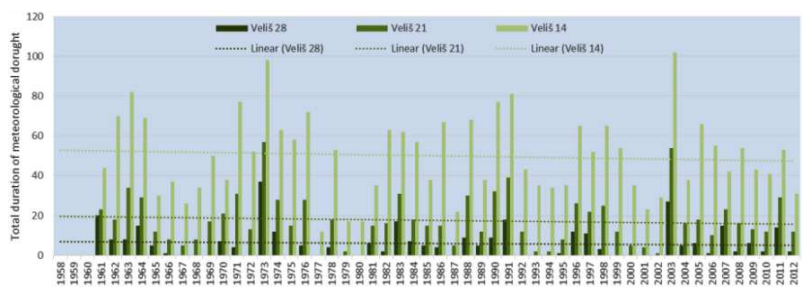

Fig. 3. Total annual duration of meteorological drought periods at Veliš station.

For the analysis of meteorological drought, three different values of $m$ were selected $(14,21$ and 28). Total values of meteorological drought duration over the period of measurement are shown in Figs. 3 and 4. Both

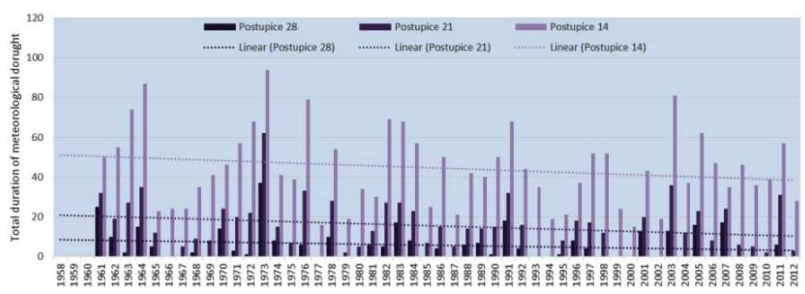

Fig. 4. Total annual duration of meteorological drought periods at Postupice station.

stations show slight decreasing trend which is more significant for Postupice station $(Z=-1.56,-1.59$ and -1.65 for $m=28,14$ and 14 days) than for Veliš station $(Z=-0.18,-0.87$ and -0.51 for $m=28,14$ and 14 days).

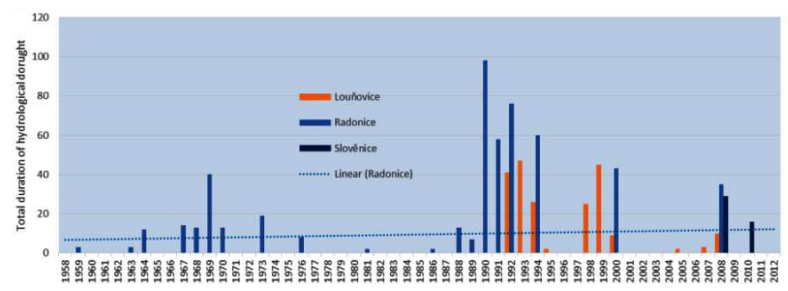

Fig. 5. Total annual duration of hydrological drought periods.

Hydrological drought was assessed based on the total duration of flows lower than $Q_{355 d}$. There is slight increase of the total duration of drought over the whole period which is however affected by very dry period 19891992 (see Fig. 5). Identified trend is not significant in this case.

\section{Conclusion}

In this paper, the results of short term drought analysis are presented for drought defined by $Q_{355 d}$ and $A P I$. No significant trend was identified in the drought duration with respect to both hydrological and meteorological drought. The only significant trend was identified in temperatures. The results show also very important period of drought at the beginning of ninetieths. Mainly this period will be further analysed.

\section{References}

[1] B. Lehner, P. Döll, J. Alcamo, T. Henrichs, F. Kaspar, Climatic Change 75, 273 (2006).

[2] Z.W. Kundzewicz, L.J. Mata, N.W. Arnell, P. Döll, B. Jimenez, K. Miller, T. Oki, Z. Sen, I. Shiklomanov, Hydrolog. Sci. J. 53, 3 (2008).

[3] P. Hlavinka, M. Trnka, D. Semerádová, M. Dubrovský, Z. Žalud, M. Možný, Agr. Forest Meteorol. 149, 431 (2009).

[4] J.E. Olesen, M. Bindi, Eur. J. Agron. 16, 239 (2002).

[5] H.B. Mann, Econometrica 13, 245 (1945).

[6] M.G. Kendall, Rank Correlation Methods, Griffin, London 1975. 